\title{
Unwanted catches, quota systems and the EU Landing Obligation: An economic and econometric analysis
}

\author{
Laura Onofri ${ }^{\mathrm{a}, *}$, Francesc Maynou ${ }^{\mathrm{b}}$ \\ ${ }^{a}$ Department of Land, Agriculture, Environment and Forestry, University of Padova, Italy \\ ${ }^{b}$ Spain Research Council, CSIC, Barcelona, Spain \\ *Corresponding author. E-mail addresses: laura.onofri@unipd.it (L. Onofri), maynouf@csic.es (F. \\ Maynou).
}

\section{ARTICLE INFO}

Keywords: Unwanted catches; Quota system; Economic incentives; Landing obligation; Environmentmarkets trade-offs

\begin{abstract}
:
The EU Landing Obligation (LO) is inspired by an environmental concern. Bycatches cannot be thrown at sea anymore but brought to land because of many (ethical) and mostly environmental concerns. Discards, in fact, can generate negative impacts on the marine ecosystems and ecological equilibrium, given increased mortality in fish populations and impact on marine biodiversity. The LO has also implications for the organization of the fishery sector (that bears costs of re-organization). The more fishers stick to the rule the better environmental management is guaranteed. The LO generates a tradeoff (and potential source of conflict) between fishery markets efficiency and marine environmental protection. The paper, therefore, explores under what conditions markets and environmental protection can "match".

The paper takes an economic perspective and provides an economic analysis of (a proposed) discard quota system for regulating unwanted catches in the European fishery sector. Using a simple model, the study evaluates whether and how the regulation designs proper mechanisms that align incentives for different economic agents (e.g. fishers and environmental concerned regulators), which are characterized by different objective functions. The study also provides selected empirical analysis. Results show that fishers choice to comply (or not) with the regulation and the proposed discard quota system, is not only affected by the legal constraint/discard ban per se but also by (1) a set of market conditions that vary day by day and (2) the degree of credible incentive design and implementation of the regulation (and related degree of credible applicability of the fines). An important aspect for the efficient working of the quota system refers to the need to design a mechanism that is also based on experience and evidence. For instance, in the Sicilian case study examined here, the probability to illegally discard UWC varies according to the type of product that is caught. In this perspective, the proposed UWC quota trade has the highest probability to work the higher is the probability (for the fisher) to be fined, the higher are the UWC price and the quantity. On the contrary, the UWC quota trade has the lowest probability to work, the lower is the probability to be fined, the lower is the quantity of UWC and the higher is the price in illegal markets.
\end{abstract}




\section{Introduction}

The objective of the landing obligation (herein LO) enshrined in the reformed Common Fisheries Policy (Art. 15 of EU Reg. 1380/2103) is to end the practice of discarding unwanted catches (UWC) back to the sea by the first of January 2019 within European marine waters. Unwanted catches include catches that are prohibited to commercialize for human consumption due to quota caps, minimum conservation reference sizes, or market demand, among other reasons. This LO or "discard ban" is a potential fisheries management contribution to achieve healthy fish stocks.

According to a FAO report on discards (FAO, 2010) the negative impacts of discards on the environment have both a biological and an ecological dimension. The biological impacts of discards vary according to the vulnerability of the species affected, however it is generally recognized that the discarding of fish at sea may have detrimental biological effects and may have effects on the stocks of commercially relevant species. Reduced bycatch and subsequent discarding of fish should lead to increased biomass of target and non-target fish and non-fish species as fishing mortality is reduced. The raising of benthic organism to the surface that are then discarded back back into the sea can cause habitat modification. The oxygen depletion of bodies caused by the decomposition of discards on the sea bottom may cause effects on the benthic community (Clucas, 1997).

Many of the ecological impacts of discards remain unquantified. The physical presence of decomposing discard materials, together with downcurrent odour trails, may lead to avoidance of the area and localized anaerobic conditions. Finally, the impact of discards on biodiversity is not well understood. Isolating the effect of discarding from other effects of fishing is difficult. The measurement of discards at the species level and quantification of survival of the species present problems. In general, discarding is likely to favour scavengers.

Discarding unwanted catch, dead or alive, is mostly caused by imperfect fisheries selectivity, legislation restrictions and market incentives which are specific to each type of fishery. For the species subjected to the LO, the use of catches of species below the minimum conservation reference size shall be restricted to purposes other than direct human consumption. The species that are not covered by the LO can continue to be discarded, while prohibited species should be returned immediately back to the sea. While the LO is an important step for fisheries conservation in European waters, it will be a challenge to ensure compliance with the obligations to record, land and account for all fish that are taken aboard the vessels ("full documentation of catches", Art. 15.5.d). Additionally, a difficult task will be to monitor changes resulting from the LO, as well as to increase traceability of landings that will be brought to land either for human or non-human consumption. In fact, one of the most important problems with discarding is that the amounts discarded are usually not recorded accurately, and often not at all. The extent of discarding, and hence the impact this has on the fishery and the marine environment is therefore very difficult to assess. Increasingly, fisheries managers are seeking ways to reduce bycatch (and hence remove the need for discarding) through the use of more selective gears. Promoting more selective fishing is one of two principal approaches to discard reduction.

In addition, compliance with the LO will impose an economic burden to fishers which must decide how to mitigate the impact of the LO. The possibilities are basically to adopt more selective fishing methods to attempt to bring the amount of UWC at/or below the 5\% de minimis exemption, to continue discarding (with the risk of incurring a penalty) or to find a commercial outlet for the utilization of UWC. At the level of individual fishers a fourth possibility arises which is the trade of UWC among producers, under the concept of tradeable discards quota. The current regulation specifies that vessels must retain and land all quota species caught, even if the current minimum mesh size rules continue to apply. In addition, quota can be renegotiated annually, fishing beyond quota breaches license conditions and could result in enforcement action. For this reason, we suggest to introduce (or disentangle from existing, general quota) a specific tradable discard quota. This economic instrument, in line with the concept of polluter pays (OECD, 1997), could be regulated under a specific policy so as to motivate the adoption of more selective fishing methods.

In this context, the paper interprets UWC under the framework of the 'polluter pays principle', where the vessels are 'polluting' the sea by producing discards (similar to $\mathrm{CO} 2$ trading pollution permits). Polluter Pays Principle (PPP) is the legal principle that makes the party liable for paying for the damage generated to the natural environment. It applies worldwide to the regulation of many 
environmental externalities, from air and water pollution, to greenhouse gas emissions and waste management regulation. ${ }^{1}$

If we apply the PPP to the case of discards in fishery, we can assimilate the discarding fisher that contravenes the LO to a polluter. In this perspective, the fisher must pay and internalize the costs of the environmental (and economic) externality. $2^{2}$ At the same time, and differently from other environmental polluters, the unwanted catches that cannot be dumped anymore (pollute the sea) are resources with an economic value and can be traded in legal and illegal markets. Therefore, the design of the UWC quota system must take into consideration this twofold aspect.

In this perspective, the paper provides an economic and econometric analysis of the quota system for regulating UWC in the European fishery sector. Through the use of a simple model, the study evaluates whether the regulation prescribes for the proper mechanisms that align incentives for different economic agents (e.g. fishers and regulators), which are characterized by different (often opposite) objective functions.

The paper is organized as follows. Section 2 provides the informative background instrumental to the paper understanding. Section 3 analyzes the conditions at which fishers might/might not comply with the LO. Section 4 discusses key points for the effective design of an UWC quota system. Section 5 analyzes the conditions and incentives for fishers to trade the quota and provides econometrics analysis. Section 6 concludes.

\section{A description of the landing obligation}

One of the advantages of tradable quota for resource users lies in their ability to raise income levels for participants. In this perspective, applications of this approach have spread to many different types of resources (fisheries, water resources, water pollution control, land use control, emissions control) and many different countries. The design and application of the quota system differs across countries and present several critical points. In order to tackle the problem, it is important to be precise with the concepts. Fig. 1 recalling the phases in the implementation of Art. 15 of EU Reg 1386/2003 in EU Mediterranean fisheries can help. We define unwanted catches that fraction of the catch that cannot be sold in fish markets, for different reasons: 1) quality or 2) legal reasons or 3) economic reasons:

1. When quality is not appropriate for the standards of the local markets, the fish is discarded [or consumed by the crew]. Typically, Mediterranean consumers will buy whole fish, fresh and in perfect condition. Bruised or damaged fish cannot be commercialized, even if they are perfectly apt for human consumption. The result is 0 income for this fraction. This fraction is usually not large and can be ignored in our scheme,

2. When fish is under Minimum Landing Size (MLS, or Minimum Conservation Reference Size, MCRS) fish SHOULD HAVE BEEN discarded under the regulations in place before 2019 (2017 for certain species: hake, red mullet, deep-water rose shrimp). But to a certain extent, fish was actually BROUGHT TO LAND for human consumption in 'black markets'. This quantity is sometimes reported as "discards" when in fact was not discarded, but sold.

1 The 'Polluter Pays Principle' was developed by the OECD in the 1970s (OECD, 1997). The principle was initially applied to international environmental problems primarily as a policy tool for enhancing efficiency, although it includes a normative notion that those who "use" a resource should pay compensation to the "owners". The principle can be implemented by various means, requiring producers or resource users to meet the cost of implementing environmental standards or technical regulations, or by introducing liability regimes making producers liable for causing environmental damage. By making polluters or resource users pay compensation for ongoing activities that deplete resources or otherwise impact on the environment, these instruments can provide incentives for introducing more environmentally sensitive practices and generate revenue to recover costs associated with administering environmental or resource management policies.

2 Externalities are those costs (or benefits) arising from an economic activity that fall on a third party and are not taken into account by those undertaking the activity. Usually, fisheries are associated with a number of 'externalities'. Fishing can contribute to degrading the environment by changing the characteristics of seabed habitats or removing non-target species and by discharging pollution. It can also fish a species to below biologically sustainable levels. The damage to or loss of 'natural capital' is borne by society in general but is external to the economic decision making of the fishery, ie not taken into account by operators. 
3. When the catches of certain low value species are too large, an important fraction of the catch is discarded to avoid "price-dumping", regardless of fish size. With the new regulation 1380/2013 this will become illegal also. With the new regulation all catches of low value species covered in ANNEX III of the Mediterranean Regulation (EU Reg. 1967/2006) must be brought to land (small-sized mackerel, horse mackerel, small pelagics in certain fisheries are relevant here).

For the purposes of this study, we should be concerned with 2 and 3. However, if we focus our analysis on hake, which is the species with more information, we are concerned with 2 only. Fisheries catches of commercial species are composed of landings plus unwanted catches: CATCHES = LANDINGS + UWC

Previous to 2019, landings were usually equated with landings-for- human-consumption and, confusingly, called "catches". From 2019 all CATCHES of regulated species should become LANDINGS. Unwanted catches (UWC) must also be landed but not sold in the traditional landings-forhuman-consumption channel.

\section{Aligning incentives between Fishers and the EU regulator}

The first step of the analysis refers to assessing the fishers' incentives to comply with the LO. The section explores the impacts of the LO on the fishers' production choices, in order to identify those conditions that make the regulation design weaker and/or stronger. Under the LO, in fact, fishers are faced with four choice options:

(1) land all catches and sell the UWC fraction for non-human consumption (comply with the regulation).

(2) land all catches and pay for the destruction of UWC (comply with the regulation).

(3) discard the UWC fraction and run the (probabilistic) risk to pay a fine (does not comply with the regulation).

(4) land all catches, sell the UWC fraction for human consumption in the "black market" and risks to pay a fine (does comply with the LO in the sense of not discarding at sea, but does not comply with the market regulation)

Using economic analysis, we can discuss and compute the costs and benefits of every choice. The purpose is analyzing the most efficient way to align incentives between the objectives of the EU regulator (avoid discards) and the objectives of the fishers (make profits). In addition, the analysis is useful for supporting the design of an efficient and effective regulatory framework.

Suppose, for the sake of simplicity, that the representative fisher wants to maximize a short term (say daily) profit function as in Eq. (1):

$$
\text { Profits }=f\left(p_{\text {fishery }} ; p_{\text {uww }} ; c_{\text {total }} ; Q_{\text {landings }} ; U W C\right)
$$

The profit function depends on the price obtained by selling the landings in the traditional channel $\left(p_{\text {fishery }}\right)$, and possible price obtained by selling the Unwanted Catches $\left(p_{u w c}\right)$; on the total costs $c_{\text {total }}$, on total landings $\left(Q_{\text {landings }}\right)$ and total amount of unwanted catches $U W C$. The total amount of UWC depends on many variables (seasonal component, individual choice of the skipper, economic component, discards aiming at keeping the price level above certain threshold).

In particular total costs are:

$$
c_{\text {total }}=c_{f}+c_{d}+c_{a}+a c_{\text {fine }}
$$

Where $c_{f}$ are the "regular" costs of fishery activities and fish handling (energy, crew and so on), $c_{d}$ are extra handling costs required by the activity of landing unwanted catches, including work and previous investment on required technologies, $c_{a}$ are administrative costs (e.g. bureaucracy at the port, including discards reporting). The two types of costs are kept independent since they depend on different sources. They also include the costs the fishers have to bear for the destruction of UWC. Fig. 1.Progressive ban on discards in EU fisheries (Art. 15 of EU Reg. 1380/2013). 


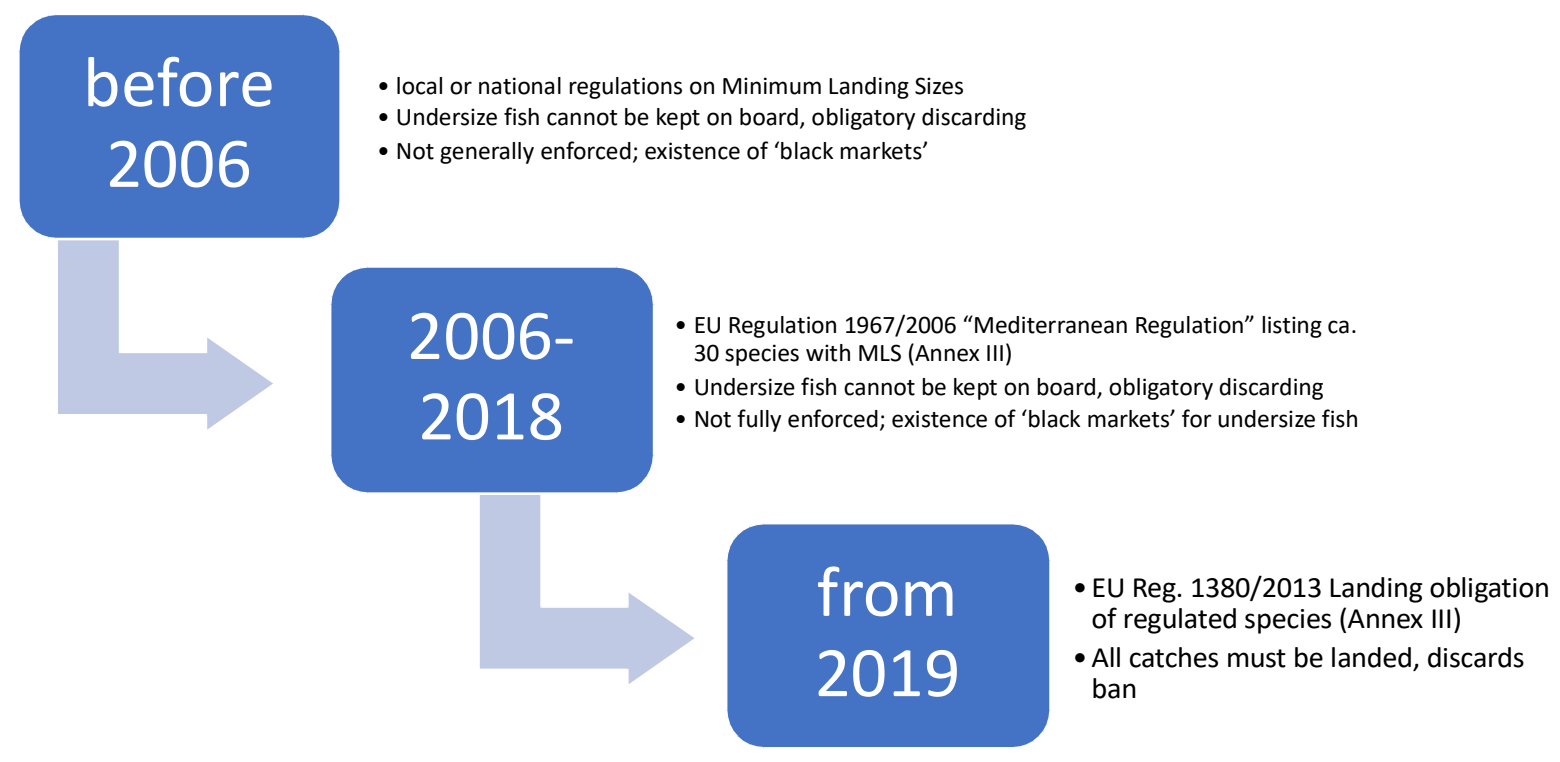

Fig. 1. Progressive ban on discards in EU fisheries (Art. 15 of EU Reg. 1380/2013).

Finally, $a c_{\text {fine }}$ are the probabilistic extra costs generated by fines for not respecting the LO. The probability $a$ is between 0 and 1 .

A. Under choice (1), ceteris paribus (e.g. assuming the normal fishing activities), total costs might increase given the $c_{d}$ and possibly increased ca components. However, on the benefits side, the fisher can add extra revenues by selling UWC at the price of $p_{u w c}$.

In this case, the regulator can align incentives by subsidizing the adoption of more selective technology, for instance through the European Maritime and Fisheries Fund (EMFF) or similar schemes. $3^{3}$

B. Under choice (2), ceteris paribus (e.g. assuming the normal fishing activities), total costs might increase given the $c d$ and possibly increased $c_{a}$ components, since the fisher pays from his own pocket to destroy the UWC. Fishers also face the opportunity cost ("income loss") of an extra revenue $\left(\mathrm{UWC} * p_{u w c}\right)$. On the benefits side, the fisher might trade off the possibility to incur in lower costs (destroying UWC) compared to the costs of organizing the UWC sales/transactions for non-human purposes and facing administrative costs.

Also in this case, the regulator can align incentives by subsidizing the adoption of more selective technology. Recall, however, that technical solutions will never be fully effective (for instance, about $50 \%$ effective for hake).

C. Under choice (3), ceteris paribus (e.g. assuming the normal fishing activities), total benefits are represented by avoided costs from landing unwanted catches, i.e. continue discarding $\left(c_{d}\right.$ and $\left.c_{a}\right)$. On the costs side, fishers face the opportunity cost (loss) of a possible extra revenue, generated by the legal sale of discards $\left(\mathrm{UWC} * p_{u w c}\right)$ and face the probabilistic costs of the fine.

3 It is worth mentioning, however, that the technological solutions tested under the EU MINOUW project and other projects reduce UWC by about 50\% only (e.g. Sola and Maynou, 2018; Vitale et al., 2018). Solutions aiming at $100 \%$ elimination of UWC are probably unrealistic. 
In this case, the regulator can align incentives by increasing the value of the fine as much as possible (not only as a direct payment but also as an avoided "premium" like a subsidy). The amount of the fine is worth, however, nothing if the probability a to be detected is very low. The closer is a to 1 , the higher are enforcement monitoring (social) costs. The fine should be inversely proportional to a, i.e. higher fines if a is low. Also, the fine should be proportional to the "benefit" of the illegal activity. This points should be addressed in the implementation of yhe LO regulation (see below).

D. Under choice (4), ceteris paribus (e.g. assuming the normal fishing activities), total benefits are represented by extra revenues generated by selling UWC in "black markets". In addition, benefits are generated by avoided costs ( $\mathrm{cd}$ and caP. On the costs side, fishers face the opportunity cost of an extra revenue (UWC*puwcPand face the probabilistic cost due to the fine.

In this case, the regulator can align incentives increasing the value of the fine as much as possible (not only as a direct payment but also as an avoided "premium" like a subsidy). The amount of the fine is worth, however, nothing if the probability a to be detected is very low. The closer is a to 1 , the higher are monitoring (social) costs. In addition, the regulator has to devote resources for monitoring, controlling and combating illegal fishery. This is a very weak point of the overall LO regulation.

The very simple micro-model can be useful for simulating a fisher level and scaling up. In fact, the fisher will:

(1) Choose option (1) when $U W C^{*} p_{u w c}>c_{d}+c_{a}$

(2) Choose option (2) when $U W C^{*} p_{u w c}<c_{d}+c_{a}$

(3) Choose option (3) when $a c_{\text {fine }}<c_{d}+c_{a}$

(4) Choose option (4) when $p_{\text {blackmarket }} * U W C>c_{d}+c_{a}+a c_{\text {fine }}$

In all cases, as a rational economic agent, the fisher will choose that option where benefits (also in the form of avoided costs) are larger than costs. The key variables that drive the fisher's choice are: the price of UWC in legal markets; the price of UWC in illegal (black) markets; the amount of UWC, the administrative costs, the costs of the fine and the probability of being detected. Such variables will affect the choice of and, therefore, the degree of compliance of different fishers will affect the results. The results will also vary according to the composition of catches and UWC. In fact, in the case of hake (and red mullet, etc.) the value of UWC fish in Choice 4 is much higher than in Choice 2 or 1 . This is because $p_{\text {blackmarket }}>p_{\text {uwc }}$.

The simple model provides a framework for understanding possible impacts of the LO application. Table 1 contains a (non-exhaustive) simulation exercise. In the Table, we combine the effects of selected variables in order to perform a qualitative analysis that helps predicting the option choice of the fishers. Under each different case, we assume that some selected variables change and other remain unchanged and derive possible outcomes that are driven by the assumed changes (and qualitative values) in the selected variables.

Fisheries managers could drive fishers towards the desired policy options (choices 1 or 2) by suitably manipulating the costs $c_{a}$ and $c_{d}$ as well as the consequences of being fined (a). Note that the prices $p_{U W C}$ and $p_{\text {blackmarket }}$ cannot be manipulated by fisheries managers. ${ }^{4}$

On the empirical side, even though a complete and thorough analysis of options with data is not feasible, given lack of systematic information, some evidence is available. More technically, using data

4 Data on black market are not available. We can suppose that reasonable prices (ex-vessel) for hake product are $4-15 € / \mathrm{kg}$ (landings) and are assumed to be around 2 to $10 € / \mathrm{kg}$ (black market). Price for industrial purposes 0.05 to $0.2 € / \mathrm{kg}$. If no market can be found and fish must be destroyed, 'polluter' must pay $0.5 € / \mathrm{kg}$. This would be a 'business as usual' scenario. If fishers decide to invest in more selective fishing methods, the amount of discards can decrease by 30-50\% depending on the technology of one species could trade with another fisherman catching less (even across countries, in Europe) and in some cases, deduct it from the quota of the following year. The monetary value of undersize fish is usually much less than the table fish (let's say 20 cents $/ \mathrm{kg}$ ). A priori, the fisherman would be interested in avoiding undersize fish. But, the problem is that the fisherman may be tempted to continue discarding. Because a quota of 10 tons with 3 tons of former discards has less monetary value than a quota of 10 tons of table fish. 
that gather information on vessels' revenues, costs and investments in the period 2008-2013 in Italy (AREA37, OTS fishing technique, from EU Annual Economic Report database), we have estimated a small balanced panel, attempting to estimate and quantify the impacts of selected costs on vessels' total revenues. Results show that:

- A $1 \%$ increase in labor costs decreases revenues by $0.47 \%$.

- A $1 \%$ increase in energy costs decreases revenues by $0.24 \%$.

- A $1 \%$ increase in repair costs decreases revenues by $0.05 \%$.

- A $1 \%$ increase in administrative costs decreases revenues by $0.20 \%$.

For instance, assuming that selected discard activities increase labor costs and administrative costs by $10 \%$ respectively, this diminishes returns by $6.7 \%$. Marginal benefits derived by complying with the LO regulation must at least increase revenues by $6.8 \%$ (see also Onofri and Maynou, 2018).

If the LO will affect the administrative costs, we can predict that for every small increase (1\%) in administrative costs, total revenues (that include revenues from the sale of catches and revenues from the sale of UWC) will decrease by $0.20 \%$. This is an effect that should be taken into consideration when designing the quota system. For instance, the regulator can simplify the administrative procedures and abate ca as much as possible, even if this is not foreseen in the actual regulation.

\section{Designing an UWC quota system under the LO}

The UWC quota system is a simple but effective policy instrument that allows aligning incentive between the fishers and the regulator on the final objective not to discard, in a context where monitoring is costly, punishment is aleatory and social norms and social preferences for law compliance do not ensure full respect of the regulation. UWC quota can represent an extra incentive for respecting the LO.

The mechanism is simple. Each fisher is allocated a discard quota (decided according to criteria we will discuss below). If at the end of an established period (day, week, month, year), the fisher quota balance is $D_{\text {actual_UWC }}>D_{\text {quota }}$, then the fisher can purchase discards quota from other fishers, whose balance equals $D_{\text {actual_UWC }}<D_{\text {quota }}$, in analogy with the PPP. Fisher that discarded more than quota can buy quota from fishers that discarded less than pre-assigned quota. A discard quota market can be created.

Table 2 summarizes the main insights for the design, implementation and management of the UWC quota system with respect to key variables that are required to design and implement the quota system.

In our opinion, key points that may hamper the design of an efficient quota trading mechanism refer to the assumption that the tradable commodity is homogeneous. Section 6.1. provides evidence in opposite direction. Another aspect of tradable permit/quota systems include the targeted degree of control, the feasibility of implementation, the likelihood of compliance, the form and intensity of monitoring and enforcement as well as the degree of technical change (see Tietenberg (2000).

It is also important to stress that in the presence of adequate enforcement, tradable UWC quota may increase the value of the resource (or lower the cost of compliance). The increase in value results from the higher profitability generated from the possibility to sell a more valuable product (because sustainable) at higher prices (see Onofri et al., 2018).

\section{Assessing the impacts of an UWC quota system under the LO}

In addition to designing the quota system, it is also important to analyze possible impacts of a quota system on the fishers' share of former catches that were discarded and now must be brought to land. Such "discard quota", in fact, is not a standard quota or ITQ's for fisheries. It is rather a penalty for those fishers that are not willing to invest in technical modifications to improve selectivity and/or "pollute" the sea by throwing unwanted catches back at sea. We must also consider that there is a de minimis exemption of $5 \%$ of the catches that can continue to be discarded.

The problem can be exemplified and simplified as follows. Suppose that Vessel 1 catches $4 \%$ of unwanted hake in one day and Vessel 2 catches 6\%. If Vessel 2 transfers $1 \%$ to Vessel 1 both can discard up to the maximum. But the crucial question is: would they be willing to do so? The 
(preliminary) answer is that it depends on many market conditions and control variables. Vessel 2 may find a market for the $1 \%$ of catches that it needs to discard or even it prefers to bring to land the entire $6 \%$ if the market for discards is lucrative enough. Instead, vessel 1 may prefer not to accept the $1 \%$ from vessel 2 if it thinks that it will need some 'room' to adapt for future larger discards during the year. In this framework, we have to take into consideration the role and impacts of enforcement and control.

Table 3 reports selected examples and outcomes, deriving from the choice the fisher must undertake, given precise circumstances, defined by selected control variables. For instance, if the fisher knows he can sell his quota because he "under-caught discards", the incentive not to follow the LO regulation might increase even more (in a situation where controls are too costly). The fisher could throw discards back to the sea (and thus generate environmental damage) and claim he/she fished below quota, therefore selling his "credit". On the other hand, that same fisher could sell UWC (out of quota) and have an incentive to respect the system. ${ }^{5}$

Table 3 reports selected scenarios, and can be also viewed as a risk assessment of the likelihood of fishers conducting "illegal activities". It is worth mentioning that, even is the cost of the fine is an important part of such assessment, we just select the probability to be caught/and fined as the key variable that influences the incentives, keeping $c_{\text {fine }}$ fixed for the sake of simplicity.

\subsection{Empirical application: discards in Sicily}

An important aspect for the efficient working of the quota system refers to the need to design a mechanism that is based on experience and evidence. This also calls for a punctual need and gathering of data. Evidence on unwanted catches is not easy to gather and it is not easy to obtain reliable UWC data on a continuous basis.

As in our illustrative example in Table 3, the evidence on the effects of existing quota systems is mixed. In certain applications, such as the U.S. sulfur allowance program and several of the fisheries, and tradable permits/quota have lived up to the high expectations of the economic theory. In other areas, such as wetlands banking, they have not (see Tietenberg, 2000). Several assumptions behind the theory may be violated in practice). This section, therefore, presents selected evidence and experiences.

We have performed econometric estimation to assess what is the impact of selected species on the probability that the fisher decides to discard. We use a simple probit model, as in Equation (3):

The probit model is a binary choice model that describes the 'choice' between two discrete alternatives. The model essentially describes the probability that $y_{i}=1$. Equation (3) says that the probability of having $y_{i}=1$ (the choice to discard in our application) depends on the vector $x_{i}$ containing the variables that might explain/affect (or not) the choice to discard (in our case the type/species of catch) in a probabilistic way. The $b$ is an estimator indicating that the model is an econometric specification. Intuitively, the model wants to empirically test the hypothesis that the probability that a fisher discards depends (positively or negatively)

Table 2. UWC quota design and application.

5 In Atlantic fisheries, for instance, each vessel can catch a fixed amount per year ('the fish quota') composed of relative values x ("unwanted catches") and y ("landings") such that Quota $=\mathrm{x}+\mathrm{y}$. We can simulate with the relative prices of $x$ and $y$; if $x$ is negative it is a penalty. The price of UWC $(x)$ is $<<$ the price of landings (y), but this is not always the case and examining the scenario of price $\mathrm{x}=$ price $y$ is relevant. In Mediterranean fisheries, Catch $1 / 4 \mathrm{X}$ py. Because catch is not limited, we can play with average volumes of production. Here $\mathrm{x}$ is typically between 0 and $30 \%$ of Catch and fishers can continue to discard up to $5 \%$. And in the Mediterranean sometimes the price of $\mathrm{x}$ can be $>\mathrm{y}$ [considering illegal markets for small fish]. 


\begin{tabular}{|c|c|}
\hline ISSUE & APPLICATION \\
\hline DATA & $\begin{array}{l}\text { Not enough data at the moment. Technology to trace the discards } \\
\text { effectively needs to be developed. For instance, even if the source } \\
\text { of discards cannot easily be traced back to an individual, although it } \\
\text { may be possible to identify groups of vessels or fleets that have } \\
\text { been fishing in a defined area. The LO requires that all catches of } \\
\text { each species above } 50 \mathrm{~kg} \text { per trip (all species, including undersized } \\
\text { fish) must be registered in the log-book and the landing declaration. } \\
\text { All catches (including undersized fish) must also be registered in the } \\
\text { transshipment declaration, the transport and take-over documents } \\
\text { and the sales note. (Art. 15.5.d). }\end{array}$ \\
\hline $\begin{array}{l}\text { HOMOGENEOUS VS } \\
\text { HETEROGENEOUS } \\
\text { COMMODITY }\end{array}$ & $\begin{array}{l}\text { The frequency of discards varies (also) across type of } \\
\text { product/species (see Section 5). Another source of heterogeneity } \\
\text { stems from spatial considerations, thus where and with what } \\
\text { composition the quota is used may matter. }\end{array}$ \\
\hline UNCERTAINTY & $\begin{array}{l}\text { A fundamental, initial uncertainty refers to the "real" determination } \\
\text { of the quota. An obvious difficulty is the fact that impacts of fishing } \\
\text { practices may be slow to appear, particularly in the absence of } \\
\text { regular monitoring. Compounding this problem is the uncertainty } \\
\text { surrounding environmental impacts and the lack of information. }\end{array}$ \\
\hline ADMINISTRATION COSTS & $\begin{array}{l}\text { Need for simple and low costs administrative procedures for fishers } \\
\text { to implement the quota system. Probably high social costs for } \\
\text { monitoring and controlling, especially in the beginning of the } \\
\text { application of the quota system. }\end{array}$ \\
\hline $\begin{array}{l}\text { TECHNOLOGICAL } \\
\text { CHANGES / PROGRESS }\end{array}$ & $\begin{array}{l}\text { The LO regulation and application of the quota system can spur } \\
\text { R\&D for more selective and sustainable fishing techniques. The } \\
\text { positive effect may be to encourage the adoption of other fishing } \\
\text { methods or the diversification to other non- fisheries related } \\
\text { activities. Fishers are generally required to pay the costs of } \\
\text { implementing these new technologies as part of their normal } \\
\text { operating costs, although some funding is normally available to the } \\
\text { sector to help meet stringent new standards or to support measures } \\
\text { that go beyond regulatory requirements. However, at the moment, } \\
\text { the only incentives come from the European Maritime \& Fisheries } \\
\text { Fund (EMFF) that subsidizes } 70-80 \% \text { of the adoption of more } \\
\text { selective fishing gear. }\end{array}$ \\
\hline $\begin{array}{l}\text { ENVIRONMENTAL } \\
\text { EFFECTS }\end{array}$ & $\begin{array}{l}\text { Interdependence between marine species for which there are } \\
\text { ecological links but distinct quota markets. Discards are a source of } \\
\text { food for marine birds and have contributed to unbalance seabird } \\
\text { populations because of trophic interference between seabird species. }\end{array}$ \\
\hline ADAPTIVE MANAGEMENT & $\begin{array}{l}\text { Management of the quota system has to keep into consideration } \\
\text { several aspects: .It is preferable to design and apply a fine (for } \\
\text { those who do not comply) that is progressive (with the physical } \\
\text { amount of discards or the vessel dimension) and not flat. .Adaptive } \\
\text { management has to carefully monitor and avoid the development of } \\
\text { illegal activities }\end{array}$ \\
\hline $\begin{array}{l}\text { DEFINITION OF THE } \\
\text { BASELINE }\end{array}$ & $\begin{array}{l}\text { The 1380/2013 Regulation defines a 5\% exemption to the } \\
\text { obligation; i.e. the quota is already defined legally. But the } \\
\text { fishermen (for instance MEDAC recommendation 132/2018, } 22 \\
\text { May 2018) are claiming for a 7\% }\end{array}$ \\
\hline INITIAL ALLOCATION & Legally attributed. \\
\hline
\end{tabular}




\begin{tabular}{|l|l|}
\hline METHOD & \\
\hline TRANSFERABILITY & Transferability assures that rights are allocated to their highest \\
valued use and provides a form of compensation for those who \\
voluntarily decide to no longer use the resource. In this perspective, \\
restrictions on transferability might reduce the efficiency of the \\
system. However, attention should be placed on several issues: \\
.small vs large vessels (large vessels might be incentivized to \\
purchase small vessel quota and concentrate quota). .Temporal \\
dimension: seasonality and fish reproduction cycle (there might be \\
period of the year when the need to trade quota is larger/ lower)
\end{tabular}

on the species he/she catches. Therefore, the function $\mathrm{F}(\cdot)$ in Equation (3) should take on values in the interval $[0,1]$ only (see Veerbek, 2002).

Our model is tested with data sampled in the period 2009-2014, with 1188 observations, onboard of selected commercial vessels in GSA16. ${ }^{6}$ It is important to highlight that the data refer to a period precedent to the entry into force of the LO. This implies that under the LO, the discards reported in the dataset should be landed and counted as part of the quota. The empirical exercise is important to provide evidence on the discards practices in a selected case-study.

In Equation (3) yi is the amount (in kilos) of selected discarded species per trip and xi are six selected species, as reported in Table 4 that presents descriptive statistics.

Table 4 reports selected statistical analysis with respect to the variables that have been used for the econometric analysis. The variable Total catch per trip reports the landings, e.g. the total amount of caught fish per trip of each commercial vessel. This has as an average of (around) $76 \mathrm{~kg}$, with a minimum of half a kilo and a maximum of 1.2 tons in the selected period. Total catches can be distinguished into two components: commercial catches and discards (UWC), with associated mean, minimum and maximum values and standard deviation for the available dataset. It is worth highlighting the high variability of the discards' quota on the total catches. It spans from 0 to $100 \%$ with an average of $30 \%$ of daily catches. The dataset includes 6 dummy variables, 7 corresponding to six selected caught species: hake, red mullet, striped red mullet, common pandora, deep water shrimps and mackerel. The table reports the frequency of each species on total catches. Finally, the dataset reports the depth of the sea where catches have occurred. Most catches (almost 33\%) occur at 600-700 m depth.

Estimation is performed with the ML (maximum likelihood) estimation method, using the statistical package STATA 12. Results show that the probability that the fisher discards is reduced if the fisher catches hake, red mullet and deep-water shrimp. On the contrary, the probability that the fisher discards increase if the catch is composed by mackerel.

Table 3. Simulations of Fisher's responses to selected scenarios.

\begin{tabular}{|l|l|l|l|l|l|}
\hline Case & $\begin{array}{l}\text { UWC } \\
\text { Quantity } \\
\text { Level }\end{array}$ & puwc & pblackmarket & a & Incentive to trade quota \\
\hline 1 & $\begin{array}{l}\text { High and } \\
>\text { Quota } \\
2\end{array}$ & High & Low & High & $\begin{array}{l}\text { Very High. } \\
\text { The high probability to be } \\
\text { fined incentivizes to comply. } \\
\text { The high price of UWC and } \\
\text { high quantity of UWC is an } \\
\text { incentive to buy/sell quota }\end{array}$ \\
\hline $\begin{array}{l}\text { Quota } \\
\text { Figh }>\end{array}$ & Low & High & High & $\begin{array}{l}\text { Fair } \\
\text { The high quantity of UWC } \\
\text { and the high price in illegal } \\
\text { markets may push the fisher to }\end{array}$ \\
\hline
\end{tabular}

6 The area GSA16 is a geographical fishery area that corresponds to Southern Sicily, more precisely, to the part of Mediterranean Sea Southern to the Western side of the Sicialian Island- See http://www.fao.org/gfcm/data/maps/gsas /en/. 


\begin{tabular}{|c|c|c|c|c|c|}
\hline & & & & & $\begin{array}{l}\text { trade in illegal markets. } \\
\text { However, the high probability } \\
\text { to be fined could represent an } \\
\text { incentive to comply. }\end{array}$ \\
\hline 3 & $\begin{array}{l}\text { Low and < } \\
\text { Quota }\end{array}$ & High & High & High & $\begin{array}{l}\text { Fair } \\
\text { The low quantity of UWC and } \\
\text { the high price in illegal } \\
\text { markets may push the fisher to } \\
\text { trade in illegal markets, unless } \\
\text { the puwc > pblack markets. } \\
\text { However, the high probability } \\
\text { to be fined could represent an } \\
\text { incentive to comply. }\end{array}$ \\
\hline 4 & $\begin{array}{l}\text { Low and }< \\
\text { Quota }\end{array}$ & Low & High & Low & $\begin{array}{l}\text { Very Low } \\
\text { The low probability to be } \\
\text { fined disincentivizes to } \\
\text { comply. The low quantity of } \\
\text { UWC and the high price in } \\
\text { illegal markets spurs the fisher } \\
\text { to trade in illegal markets. }\end{array}$ \\
\hline 5 & $\begin{array}{l}\text { Low and }< \\
\text { Quota }\end{array}$ & High & High & Low & $\begin{array}{l}\text { Fair/Low } \\
\text { The low probability to be } \\
\text { fined disincentivizes to } \\
\text { comply. However, the low } \\
\text { quantity of UWC and the high } \\
\text { UWC price may spur the fisher } \\
\text { to trade quota, unless the price } \\
\text { in illegal markets is } \\
\text { significantly higher than the } \\
\text { price of UWC. }\end{array}$ \\
\hline 6 & $\begin{array}{l}\text { Low and }< \\
\text { Quota }\end{array}$ & Low & Low & Low & $\begin{array}{l}\text { Fair/Low } \\
\text { Even if the low probability to } \\
\text { be fined disincentivizes to } \\
\text { comply, the low quantity of } \\
\text { UWC and the low prices (in } \\
\text { legal and illegal markets) may } \\
\text { spur the spur the fisher to } \\
\text { comply given the low value of } \\
\text { the expected pay-off. }\end{array}$ \\
\hline 7 & $\begin{array}{l}\text { High and > } \\
\text { Quota }\end{array}$ & Low & Low & Low & $\begin{array}{l}\text { Fair } \\
\text { The low probability to be } \\
\text { fined disincentivizes to } \\
\text { comply, however, the high } \\
\text { quantity of UWC may spur the } \\
\text { fisher not to comply if the } \\
\text { price in illegal markets is } \\
\text { higher than the one in legal } \\
\text { markets. }\end{array}$ \\
\hline 8 & $\begin{array}{l}\text { High and }> \\
\text { Quota }\end{array}$ & High & High & High & $\begin{array}{l}\text { Fair/Low } \\
\text { The high probability to be } \\
\text { fined incentivizes to comply. } \\
\text { The fisher also has a high } \\
\text { incentive to trade quota, given } \\
\text { high quantity of UWC, only if } \\
\text { the price in legal markets is }\end{array}$ \\
\hline
\end{tabular}




\begin{tabular}{|l|l|l|l|l|l|}
\hline & & & & $\begin{array}{l}\text { higher than the price in illegal } \\
\text { markets. }\end{array}$ \\
\hline
\end{tabular}

Table 4. Descriptive Statistics.

\begin{tabular}{|l|l|l|l|l|}
\hline Variable & $\begin{array}{l}\text { Mea } \\
\mathrm{n}\end{array}$ & $\begin{array}{l}\text { Standard } \\
\text { Deviation }\end{array}$ & Min. & Max. \\
\hline Totat Catch per trip (kg) & 75.80 & 116.76 & 0.4 & 1142.5 \\
\hline Commercial Catch per trip (kg) & 63.08 & 99.95 & 0.4 & 1126 \\
\hline Discard per trip (kg) & 36 & 100.92 & 0 & 1013.3 \\
\hline$\%$ discard on total catches & 29 & 30 & 0 & 100 \\
\hline Hake (HKE) & Dummy Variable $\mathrm{HKE}=1$ in $27.44 \%$ of total catches \\
\hline Red Mullet (MUT) & \multicolumn{2}{|l|}{ Dummy Variable. MUT $=1$ in $17.53 \%$ of total catches } \\
\hline Striped Red Mullet (MUR) & Dummy Variable. MUR $=1$ in $15.04 \%$ of total catches \\
\hline Common Pandora (PAC) & \multicolumn{2}{|l|}{ Dummy Variable. MUR $=1$ in $11.33 \%$ of total catches } \\
\hline Deep Water Shrimp (DPS) & Dummy Variable. MUR $=1$ in $22.35 \%$ of total catches \\
\hline Mackerel (HOM) & Dummy Variable. MUR $=1$ in $6.39 \%$ of total catches \\
\hline Depth & From 10 to 700 m. Higher frequency: $600-700$ m $(32.89 \%)$ \\
\hline
\end{tabular}

In particular, the computation of marginal effects for statistically significant coefficients, provides the following insights:

- If the fisher catches hake, this decreases the probability to discard by $0.7 \%$

- If the fisher catches red mullet, this decreases the probability to discard by $0.2 \%$

- If the fisher catches deep-water shrimps, this decreases the probability to discard by $1.2 \%$

- If the fisher catches mackerel, this increases the probability to discard by $0.9 \%$

The changes in the probability of discarding seem very low, spanning from 0.2 to $1.2 \%$. An interpretation of the empirical results might suggest that discard is still an acquired practice and the type of fish to be discarded only varies on the margin the choice to (not to an $\mathrm{d}$ how much) discard.

\section{Conclusion}

Using a simple model, the study evaluates whether the LO regulation designs proper mechanisms that align incentives for different economic agents (e.g. fishers and regulators), which are characterized by different (often opposite) objective functions. The paper also provides an economic analysis of a proposed quota system for regulating discards in the European fishery sector The study also provides selected empirical analysis.

Results show that:

- Fishers are confronted with the choice to comply with the regulation (or not to comply). Such choice is not only affected by the legal constraint/discard ban per se but also by (1) a set of market conditions that vary day by day and (2) the degree of credible implementation of the regulation (and related degree of credible applicability of the fines). The study shows how such variables may affect the working of the regulation and qualitatively simulates how a mix of impacts (with changes in selected parameters) affect the final objective of complying with the LO regulation and legally trading the UWC quota.

- In this perspective, the proposed UWC quota trade has the highest probability to work the higher is the probability (for the fisher) to be fined, the higher are the UWC price and the quantity. On the contrary, the UWC quota trade has the lowest probability to work, the lower is

7 A dummy variable is a variable taking the value of 0 or 1 to indicate the absence or presence of that explanatory effect/variable in the estimated model and effects. Dummy independent variables, which for some observation has a value of 0 , will cause that variable's coefficient to have no role in influencing the dependent variable, while when the dummy takes on a value 1 its coefficient this implies it has a role in influencing the dependent variable. 
the probability to be fined, the lower is the quantity of UWC and the higher is the price in illegal markets. An important aspect for the efficient working of the quota system refers to the need to design a mechanism that is also based on experience and evidence. For instance, in the Sicilian case, the probability to discard UWC varies according to the type of product that is caught.

The above point also calls for a punctual need and gathering of data. At the moment, to our knowledge there is no legal requirement on how to gather and record discard data. Evidence on unwanted catches is not easy to gather and it is not easy to obtain reliable UWC data on a continuous basis. Monitoring and enforcement of activities remain major challenges to the implementation of quota systems, which are very "hungry for data" and vulnerable to cheating. Finally, a proper quota system design that incentivize the fishers to follow the LO might also benefit the environment and result in an incentive mechanism regulation that overcomes the difficult trade-off between market requirements and environmental protection in the fishery sector.

\section{Declaration of competing interest}

We hereby declare no conflict of interest in the paper revision and resubmission. This research was funded by EU H2020 Research and Innovation Action "MINOUW" (contract no 634495).

\section{References}

Clucas, I., 1997. A Study of the Options for Utilization of Bycatch and Discards from Marine Capture Fisheries. FAO Fisheries Circular. No. 928. FAO, Rome, 1997. 59pp.

FAO, 2010. Discards in the World's Marine Fishery: an Update. http://www.fao.org/3/ y5936e/y5936e0b.htm.

OECD, 1997. Towards Sustainable Fisheries: Economic Aspects of the Management of Living Marine Resources. Organization of Economic Co-operation and Development, Paris.

Onofri, L., Maynou, F., 2018. The impact of the EU landing obligation on the supply side of the fishery market: evidence from catalonia. Int. J. Ecol. Econ. Stat.

Onofri, L., Accadia, P., Ubeda, P., Gutierrez, M.J., Sabatella, E., Maynou, F., 2018. "On the Economic of Consumers's Willingness to Pay for a Selective and Sustainable Fishery: a Comparative Empirical Study" Scientia Marina 82S1, pp. 96-99.

Sola, I., Maynou, F., 2018. Assessment of the relative catch performance of hake, red mullet and striped red mullet in a modified trawl extension with T90 netting. Sci. Mar. 82S1, 19-26.

Tietenberg, 2000. Environmental and Natural Resource Economics, fifth ed. Addison- Wesley, Reading, MA.

Veerbek, M., 2002. A Guide to Modern Econometrics. Wiley \& Sons.

Vitale, S., Milisenda, G., Gristina, M., Baiata, P., Bonanomi, S., Colloca, F., Gancitano, V., Scannela, D., Fiorentino, F., Sala, A., 2018. Toward more selective trawl fishery in south-central Mediterranean Sea: the use of sorting grids to reduce the by-catch of undersize deep-water rose shrimp (Parapenaeus longirostris) and European hake (Merluccius merluccius). Sci. Mar. 82S1, 215-223. 